\title{
Phytochemical Screening and Antibacterial Studies on Leaf and Root Extracts of Asclepias Curassavica (L).
}

\author{
S. HEMADRI REDDY ${ }^{1}$, M. CHAKRAVARTHI ${ }^{2}, \mathrm{~K} . \mathrm{N}$. \\ CHANDRASHEKARA ${ }^{3 *}$ AND C.V. NAIDU ${ }^{4}$ \\ ${ }^{1 *}$ Department of Plant Sciences, College of Agriculture and Natural Resources, Wollega University, PO Box- \\ 395, Nekemte, Ethiopia. \\ ${ }^{2}$ Division of Crop Improvement, Sugarcane Breeding Institute, Coimbatore - 641007, Tamilnadu, India. \\ ${ }^{3}$ Department of Plant Physiology \& Biotechnology, UPASI Tea Research Institute, Valparai - 642 127, \\ Tamilnadu, India. \\ ${ }^{4}$ Department of Biotechnology, Dravidian University, Kuppam-517426, Andhra Pradesh, India.
}

\begin{abstract}
Asclepias curassavica like most of the medicinal plants has highest significance for its valuable secondary metabolites (glycosides and saponins). The clones produced thereof hence need to maintain their absolute genetic stability so that no unwanted variation in secondary metabolite yield can occur. Plant extracts that inhibit the growth of pathogenic microorganisms without harming the host may have potential application as therapeutic agents. Hence the present study was performed to investigate the antibacterial activity of leaves and roots of different solvent (petroleum spirit, hexane, chloroform, ethyl acetate and methanol) extracts by employing well diffusion techniques with some human pathogenic and non-pathogenic bacterial strains. Maximum diversity of chemical constituents was found in methanol and petroleum spirit extracts in both samples tested. The methanol and petroleum spirit extracts were found active against most of the tested pathogenic bacteria as they showed potential phytochemical constituents. Among the tested species Escherichia coli, Klebsiella pneumoniae showed greatest sensitivity against methanol and petroleum spirit root extracts which prove that the plant extracts are potential candidates for antibiotic resistance against such bacteria.
\end{abstract}

Keywords: Phytochemical screening, antibacterial activity, Asclepiadoideae, therapeutic

\section{Introduction}

Asclepias curassavica (L.) (Tropical milkweed) is an erect, evergreen sub shrub belonging to the sub family Asclepiadoideae, family Apocynaeceae [1]. The sub family Asclepiadoideae constitutes many medicinally important plants comprising more than 250 genera and 3,000 species, of which 43 genera and 243 species are present in India. It has a woody based stem with milky sap leaves 6-14 x 1-3.5 cm, decussate, lanceolate, puberculous along nerves, acute at both ends. Plant grows to $1 \mathrm{~m}$ in height, occupies $45-60 \mathrm{~cm}$. In general, Asclepiadoideae plants are the source of cytotoxic and cardiac glycosides and contain highly valuable potential products for curing many diseases. Resinoid (galitoxin), a toxic principle in poisonous species is found in the milky latex of its stem. Several glycosides (cardiac glycosides) and an alkaloid have been isolated. Root extracts of this plant are widely used in South America an emetic and laxative. A decoction of the plant is used as an abortifacient. Roots are known as "Pleurisy root" and used as an expectorant for pneumonia, lung problems, employed to treat warts, fever, etc. Plant is anti-ovulatory, astringent, cardiotonic and used for abdominal tumor, haemorrhages, and headache. The plant contains highly potential esterified polyhydroxy pregnane glycoside that shows antitumour and anticancer property. The use of plants as medicines has paved way for the isolation of active compounds, beginning with the extraction of morphine from opium in the early $19^{\text {th }}$ century [2]. It is estimated that around 2,50,000 flowering plant species reported occur globally and approximately half of these are found in tropical forests. Medicinal plants are of great interest as pharmaceutical industries depend in part on plants for the production of secondary metabolites [3].

India has about 8,000 species of known medicinal plants and about 1,000 plants have been used in the traditional system of medicine like Ayurveda, Unani and Sidha, while tribals use 7,500 plant species for medicinal purposes using the current global rates of species extinction at around 10 to 12 per cent of the plants (800-1,000 species) are likely to be threatened [4]. The phytochemicals produced from the medicinal herbs are curative constituents for several diseases. Natural products derived from higher plants may form the source to search for novel drugs based on their new modes of pharmacological action. This action may be due to the presence of carbohydrates, carbohydrate derivatives, gums, mucilages, pectins, various forms of glycosides, tannins, phenolic compounds, lipids, fixed and volatile oils, resins, alkaloids etc. The significance of phytochemical analysis and its importance for the establishment of alternative medicine was expressed [5]. A 
thorough study of literature showed that a large number of taxa in the family Asclepiadoideae are medicinally important and contain different kinds of secondary metabolites. Glycosides (steroidal, pregnane), flavonoids are the major compounds reported in this family. The production of an essential oil containing 2-hydroxy 4methoxy benzaldehyde from the in vitro derived roots of Hemidesmus indicus has been carried out [6]. The batch culture of $H$. indicus roots had been conducted for the continuous production of roots and root specific compounds [7]. Selected medicinal plants of Asclepiadaceae family have been screened [8]. Recently, the antimicrobial activity of root extracts in A. curassavica $(L)$. was reported [9]. Here in this investigation, we report that both the leaf as well as root extracts are potential antimicrobial agents that can be purified and employed as broad spectrum antibiotics.

\section{Materials And Methods}

\section{Plant Material}

The leaves and roots of A. curassavica were collected from Tirumala hills, Chittoor District, Andhra Pradesh, India. The material was thoroughly washed with tap water to remove soil particles and then shade dried on filter paper. The leaves and roots were chopped into small pieces and were ground to fine powder (each $100 \mathrm{~g}$ ) and stored in polythene containers at room temperature until required for further use.

\section{Test Microorganisms}

The test microbes employed were Bacillus subtilis, Staphylococcus aureus, Proteus vulgaris, Escherichia coli and Klebsiella pneumoniae. The microorganisms listed were obtained from the microbial type culture collection centre, Institute of Microbial Technology (IMTECH), Chandigarh, India and maintained on their respective media (as per guidelines of IMTECH) in slants at $4^{\circ} \mathrm{C}$.

\section{Extraction And Fractionation Of The Plant Material}

The samples were analyzed chemically to detect the different classes of secondary metabolites. About $100 \mathrm{~g}$ of the each powdered test material was placed onto Soxhlet apparatus and fractionated sequentially in 200 $\mathrm{ml}$ of ethanol, ethyl acetate, chloroform, hexane and petroleum spirit ,successively over 6-12 hrs (or) the extraction was continued until the liquid was clear. The extracts obtained were distilled and concentrated under the reduced pressure using Rota- evaporator at $40^{\circ} \mathrm{C}$ to dryness and the residue was used for the tests [10].

\section{Phytochemical Screening Of The Plant Extracts}

Preliminary phytochemical analysis was undertaken using standard qualitative methods $[10,11,12,5$ and 13]. The different crude extracts obtained were qualitatively tested for the presence of various phytochemical constituents using standard protocols [14, 15, 16 and 13]. The extractive values were calculated by standard methods [17]. The concentrated crude extracts obtained through were weighed and dissolved in the respective solvent used for the extraction $(1 \mathrm{~g} / 100 \mathrm{ml}, \mathrm{w} / \mathrm{v})$.

\section{Screening Of Antibacterial Activity}

The screening of the antimicrobial activity of crude extracts of leaf and root material of Asclepias curassavica were carried out by well diffusion method [18] and their inhibitory effects were compared individually on active cultures of 5 different pathogenic microbes with penicillin and streptomycin as standards.

\section{Results And Discussion}

The pharmacological action of crude drugs and other therapeutic uses are due to their therapeutically active constituents. So, the preliminary phytochemical analysis revealed pronounced importance because the crude drugs possess varied composition of secondary metabolites [19 and 20]. Preliminary phytochemical screening in A. curassavica leaves and roots were carried out using different solvent extractions.

The preliminary phytochemical analysis of A. curassavica leaves indicated the presence of glycosides and phenols in three different solvent extractions i.e., chloroform, ethyl acetate and methanol extractions (Table 1). Further, methanol extract showed the presence of steroids and glycosides at high quantity, whereas flavonoids and resins in low quantity. No significant groups of secondary metabolites were detected in chloroform and hexane extracts. Comparatively low concentrations of carboxylic acids, phenols and glycosides were present in chloroform extract than hexane extract. A positive result in less quantity of phenols, resins, quinones, steroids, tannins and fixed oils was obtained with petroleum sprit and ethyl acetate extracts. Alkaloids, tannins and coumarins were found completely absent in all the five solvent extracts.

The preliminary phytochemical analysis of root extracts indicated the presence of carboxylic acids, coumarins, flavonoids, phenols, resins, steroids, tannins and glycosides from ethyl acetate and methanol extracts but in less quantity, except glycosides which are abundant in petroleum spirit, hexane, ethyl acetate and methanol extracts (Table 2). The abundance of glycosides was higher in root extracts and restricted to petroleum spirit, ethyl acetate and methanol extracts. Resins were found in chloroform and methanol extracts of 
root. Comparatively, root extracts of all solvents checked contain more secondary metabolites than leaf extracts.

Glycosides are the major group of secondary metabolites present in the family Asclepiadaceae. They are compounds containing a carbohydrate (glycone) and a non carbohydrate (aglycone) residue in the same molecule attached by acetyl ring. The chemical nature of the aglycone group is used as the basis of systematization. The aglycone may be glycerol, a saponin, a sterol, or a phenol. In the present investigation, preliminary phytochemical analysis has revealed the presence of steroids, saponins and phenols as major chemical groups. Hence it can be assumed that the glycosides in the plant A. curassavica may be either steroidal glycoside as reported in the related taxa Cryptolepis buchanani [21] or occurrence of saponin glycosides were reported in Marsdenia condurango, another asclepiad [22]. The other glycosides reported from asclepiads include Calotropis gigantean [23], Oxystelma esculentum [24] and Cynanchum formosanum [25]. Saponins are glycosides of both triterpenes and sterols and have been detected in over seventy families of plants [26]. They are surface active agents with soap like properties and can be detected by their ability to cause foaming and haemolysis of blood cells. The search in plants for saponins has been stimulated by the need for readily accessible sources for sapogenins, which can be converted in the laboratory to animal sterols of therapeutic importance (eg: cortisone, contraceptive, estrogens etc.). The glycoside patterns of the saponin are often complex, may have as many as five sugar units attached and glucuronic acid is a common component. Saponin glycosides have been reported in the related member $H$. indicus [27]. Alkaloids and tannins are entirely lacking from leaf material, but less quantity of tannins were present in root material. The antimicrobial property of glycosides ensures its use as an anti infective agent [28 and 29]. Coumarins, present in less quantity in root material, are known to possess antitumor, antibacterial and anthelmintic properties [12]. In the present study, methanol extract was found to exhibit growth inhibition on all tested microorganisms, except $P$. vulgaris (Table 3). Petroleum spirit extract showed activity against three out of five tested organisms, but comparatively with less activity than methanolic extract. The poor response was obtained by ethyl acetate extract which showed activity against only two microorganisms and these include $S$. aureus and B. subtilis. The activity with other leaf extracts i.e. chloroform and hexane were found totally nil. Among all the tested organisms, $P$. vulgaris was found to be resistant and remained unaffected by all the solvent extracts. $K$. pneumoniae showed moderate inhibitory zone with three solvent extracts. The effect of petroleum spirit root extract against $E$. coli was so prominent that its inhibition was more or less equal to that of respective standards. The inhibitory zone obtained by methanolic extract against K. pneumoniae and E. coli were note worthy. Among the various solvent extracts of leaf and root tested against different bacteria, the root extracts showed better inhibition effects than leaf extracts comparatively. The maximum activity of methanol, ethyl acetate and petroleum spirit extracts on $K$. pneumoniae and E. coli indicates the presence of antimicrobial agents in this plant which are useful in curing various skin infections, as these organisms often cause various skin infections in human beings.

Results obtained with methanolic extracts indicate the presence of activity against all the microorganisms tested at various levels. The preliminary phytochemical test indicates glycosides and saponins as the major constituents in the methanolic extract of both root and leaf materials. Hence it can be concluded that the kind of glycoside it contains is the principle antibiotic agent in this plant. The antimicrobial nature of glycosides was proved in the related member Calotropis procera [23]. The antibacterial activity of methanolic extracts of leaf material from Solanostermma argel, another member of Asclepiadaceae has been reported [30]. The antibacterial activity of Alcoholic extract was also proved successfully in two important Asclepiadaceans i.e. Laptadaenia pyrotechnica and Sarcostema acidium [31]. Other Asclepiadaceae family members that contain antibacterial activity established successfully include Decalepis hamiltonii [32] H. indicus [33 and 34], Gymnema sylvestrae [35] and Oxystelma esculentum [36].

\section{Conclusion}

Asclepias curassavica like most of the medicinal plants has highest significance for its valuable secondary metabolites (glycosides and saponins). Plant extracts that inhibit the growth of pathogenic microorganisms without harming the host may have potential application as therapeutic agents. Hence, the present investigation attempted to evaluate antimicrobial activity of crude extracts, extracted from leaves and roots of A. curassavica using some human pathogenic and non-pathogenic bacterial strains. Successive petroleum spirit, hexane, chloroform, ethyl acetate and methanol extracts of A. curassavica leaf and root extracts were tested for their phytochemical constituents. Maximum diversity of chemical constituents was found in methanol and petroleum spirit extracts in both samples tested. The methanol and petroleum spirit extracts were found active against most of the tested pathogenic bacteria as they showed potential phytochemical constituents. Among the tested species E. coli, K. pneumoniae showed greatest sensitivity against methanol and petroleum spirit root extracts. Thus the leaf and root extracts of $A$. curassavica are potential antibacterial agents that can be purified to be used as antibiotics. 


\section{Acknowledgments}

S Hemadri Reddy would like to thank Department of Biotechnology, S.V. University, Tirupati, Andhra Pradesh for providing Doctoral fellowship to complete this work.

\section{References}

[1] M.E. Endress and P.V. Bruyns, A revised classification of the Apocynaceae s.1. Botanical Review, 66: 1-56, (2000).

[2] A.D. Kinghorn, Pharmacognosy in $21^{\text {st }}$ Century. J Pharm Pharmacol, 53: 135-148, (2001).

[3] G.R. Rout and P. Das, Micropropagation of Madhuca longifolia (Koenig) Mac Bride Var. Larifolia Roxb. Plant Cell Rep., 12: 513516, (2000).

[4] S.K. Verma, S.K. Sharma, Charansingh and A. Mehta, Breeding, Improvement and Germplasm conservation of Medicinal and Aromatic Plants. Indian Forester, (2004)

[5] J.B. Harborne, Phytochemical methods, $2^{\text {nd }}$ Edn, Chapman and Hall, London, U.K, (1984).

[6] S. Sreekumar, S. Seeni and P. Pushpangadan, Micropropagation of Hemidesmus indicus for cultivation and production of 2hydroxy, 4-methoxy benzaldehyde. Plant Cell Tiss Org Cult, 62: 211-218, (2000).

[7] S. Sreekumar, S. Seeni and P. Pushpangadan, Production of 2-hydroxy, 4-methoxy benzaldehyde using root cultures of Hemidesmus indicus. Biotech. Lett, 20: 631-635, (1998).

[8] K.M. Averineni Ravikumar, Subbu Rathinam, and G. Prabakar G, Phytochemical Screening of selected medicinal plant of Asclepiadaceae family. Asian journal of Microbiol Biotechnol Environ Sci, 9: 177-180, (2007).

[9] H.F. Waltor, Principle and methods of chemical analysis, Prentice-Hall of India Pvt. Ltd., New Delhi, (1971)

[10] R.P. Amarasingham, N.G. Bisset, P.H. Millard and M.C. Woods, Phytochemical survey of Malaya part - III, Alkaloids and Saponins, J Econ Bot, 18: 270-278, (1964)

[11] A.K. Das and A. Bhattacharjee, A systematic approach to phytochemical screening. Trop Sci, 12: 54-58, (1970).

[12] S.C. Chhabra, F.C. Uiso and E.N. Mshiu, Phytochemical screening of Tanzanian medicinal plants. J Ethnopharmacol, 11: 157-179, (1984).

[13] W. Kemp, (eds.), Qualitative Organic analysis (Spectrochemical Techniques), McGraw Hill, London, (1986).

[14] K.R. Brain and T.D. Turner, (eds.), The practical evaluation of phytopharmaceuticals, Wright Scentechnica, Bristol, (1975).

[15] A. Sofowora, (eds.), Medicinal plants and traditional medicines in Africa, John Wiley and Sons Ltd., New York, U.S.A, (1982).

[16] G.D. Trease and W.C. Evans, Pharmacognosy, Bailer Tindall, London, U.K, (1983)

[17] Egyptian Pharmacopoeia, General Organization for Governmental Printing Office, Cairo, (1984)

[18] F. Kavanagh, Analytical microbiology Part II, New York, Academic Press, pp .126, (1972).

[19] M. Wink, (eds.), Functions of plant secondary metabolities and their exploitation in technology. Sheffield Academic Press, Sheffield, England, (1999).

[20] M.F. Balandrin, J.A. Klocka, E.S. Wurtele and W.H. Bollinger, Natural Plant Chemicals: Sources of industrial and medicinal materials. Science, 228: 1154-1160, (1985).

[21] R.M. Venkateswara, K. Sankara Rao and C.S. Vaidyanathan, Cryptosin -a new cardenolide in tissue culture and intact plant of Cryptolepis buchanani Roem and Schult. Plant Cell Rep, 6: 291-293, (1987).

[22] T. Ortega, M.E. Carretaro, E. Pascual, A.M. Villar and X. Chiridoga, Anti-inflammatory activity of ethanolic extracts of plants used in traditional medicine in eduador. Phytotherapy Research, 10: 121-122, (1996).

[23] N. Akhtar and K. Malik, Proceragenin, an antibacterial cardenolide from Calotropis procera. Phytochemistry, 31: 2821-2824, (1992).

[24] R. Trivedi, A. Khare and M.P. Khare, A cardenolide tetraglycoside from Oxystelma esculentum. Phytochemistry, 30: 301-303, (1991).

[25] Z.S. Chen, J.S. Lai and Y.H. Kuo, Cynanformosides A and B, two new pregnane glycosides from the aerial part of Cynanchum formosanum. Chem, Pharm. Bull, 39: 3034-3036, (1991).

[26] K. Hostettmann and A. Marston, Saponins, University press, Cambridge, (1995).

[27] K. Prakash, A. Sethi , D. Deepak, A. Khare, and M.P. Khare, Two Pregnane glycosides from Hemidesmus indicus. Phytochemistry, 30: 297-300, (1991).

[28] A. Murakami, H. Ohigashi, S. Tanaka, A. Tatematsu and K. Koshimizu, Bitter cyanoglucosides from Lophira alata. Phytochemistry, 32: 1461 - 1466, (1993).

[29] G. Rucker, S. Kehbaum, J. Sakulas, B. Lawong and F. Goeltenboth, Acetylenic glucosides from Microglossa pyrifolia. Planta Medica, 58: 266-269, (1992)

[30] F.K.A. El Hady, A.G. Hagazi, A. Ata and M.L. Enbawy, Studies for determining antimicrobial methods in different proportions. Qutar University Science Journal, 14: 143-146, (1994).

[31] D. Gehlot and A. Bohra, Toxic effect of various plant part extracts on the causal organism of typhoid fever. Curr. Sci, 78: 780-781, (2000).

[32] D. Thangadurai, S. Anith, T. Pullaiah, P.N. Reddy and O.S. Ramachandraiah, Essential oil constituents and in vitro antimicrobial activity of Decalepis hamiltonii roots against food borne pathogens. J. Agric. Food Chem, 50: 3147-3149, (2002).

[33] S.P. Hiremath, K.R. Rudresh and S. Badami, Antimicrobial activity of various extracts of Striga sulphurea and Hemidesmus indicus. Indian J. Pharm. Sci, 59: 45-47, (1997).

[34] Y.R. Prasad, G.S. Alankara Rao and P. Baby, Antimicrobial studies on essential oil Hemidesmus indicus. R. Br. Indian Perfumer, 27: 197-199, (1983).

[35] C. Kohlert, V.I. Rensen, R. Marz, G. Sachindler, E.V. Gravef and M. Veit, Bioactivity an pharmacokinetics of natural volatile terpenes in humans and animals. Planta Medica, 66: 405-505, (2000).

[36] L. Bhakshu Md, Ethno-medico botanical and phytochemical evaluation of certain plants from Eastern Ghats, India. Ph.D. thesis submitted to S.K. University, Anantapur, India. (2002). 
Phytochemical Screening And Antibacterial Studies On Leaf And Root Extracts Of Asclepias

Table 1: Phytochemical screening of field grown Asclepias curassavica leaf extracts.

\begin{tabular}{|c|c|c|c|c|c|}
\hline $\begin{array}{l}\text { Name of the } \\
\text { Compound }\end{array}$ & $\begin{array}{c}\text { PS } \\
\text { extract }\end{array}$ & $\begin{array}{l}\text { Hexane } \\
\text { extract }\end{array}$ & $\begin{array}{c}\text { Chloroform } \\
\text { Extract }\end{array}$ & $\begin{array}{c}\text { EA } \\
\text { extract }\end{array}$ & $\begin{array}{c}\text { Methanol } \\
\text { extract }\end{array}$ \\
\hline Alkaloids & - & - & - & - & - \\
\hline $\begin{array}{l}\text { Carboxylic } \\
\text { acids }\end{array}$ & - & ++ & + & - & + \\
\hline Coumarins & - & - & - & - & - \\
\hline Fixed oils & + & - & - & + & - \\
\hline Flavonoids & - & - & - & - & + \\
\hline Phenols & + & ++ & + & + & + \\
\hline Quinones & + & - & - & + & + \\
\hline Resins & + & - & - & + & + \\
\hline Steroids & + & - & - & + & ++ \\
\hline Tannins & - & - & - & - & - \\
\hline Glycosides & - & - & + & + & ++ \\
\hline
\end{tabular}

$(\mathrm{PS}=$ Petroleum spirit, EA = Ethyl acetate $)$

(- indicates no activity, + indicates weak activity, ++ indicates moderate activity)

Table 2: Phytochemical screening of field grown Asclepias curassavica root extracts

\begin{tabular}{|c|c|c|c|c|c|}
\hline $\begin{array}{l}\text { Name of the } \\
\text { Compound }\end{array}$ & $\begin{array}{c}\text { PS } \\
\text { extract }\end{array}$ & $\begin{array}{l}\text { Hexane } \\
\text { extract }\end{array}$ & $\begin{array}{c}\text { Chloroform } \\
\text { Extract }\end{array}$ & $\begin{array}{c}\text { EA } \\
\text { extract }\end{array}$ & $\begin{array}{c}\text { Methanol } \\
\text { extract }\end{array}$ \\
\hline Alkaloids & - & - & - & - & - \\
\hline Carboxylic acids & - & ++ & - & + & + \\
\hline Coumarins & - & - & + & + & + \\
\hline Fixed oils & + & - & - & + & - \\
\hline Flavonoids & - & - & - & + & + \\
\hline Phenols & + & ++ & + & + & + \\
\hline Quinones & + & - & - & + & - \\
\hline Resins & - & - & + & - & + \\
\hline Steroids & + & - & - & + & + \\
\hline Tannins & + & + & - & + & + \\
\hline
\end{tabular}




$$
\begin{array}{lllllll}
\text { Glycosides } & +++ & ++ & & - & ++ & +++
\end{array}
$$

(PS = Petroleum spirit, EA = Ethyl acetate $)$

(- indicates no activity, + indicates weak activity, ++ indicates moderate activity, +++ indicates strong activity)

Table 3: Antibacterial Screening of Asclepias curassavica Leaf and root extracts (Zone of inhibition in

\begin{tabular}{|c|c|c|c|c|c|c|c|}
\hline \multicolumn{8}{|c|}{ mm) } \\
\hline \multirow[t]{2}{*}{ ORGANISM } & \multicolumn{5}{|c|}{ LEAF } & \multicolumn{2}{|c|}{ Standard } \\
\hline & P.S.E & H.E & Ch.E & E.A.E & M.E & Streptomycin & Penicillin \\
\hline Bacillus subtilis & 7 & -- & -- & 7 & 7 & 14 & 10 \\
\hline Staphylococcus aureus & 7 & -- & -- & 7 & 7 & 12 & 10 \\
\hline Proteus vulgaris & -- & -- & -- & -- & -- & 9 & -- \\
\hline Escherichia coli & 7 & -- & -- & -- & 7 & 10 & 6 \\
\hline \multirow[t]{3}{*}{ Klebsiella pneumoniae } & -- & -- & -- & 6 & 6 & 9 & -- \\
\hline & \multicolumn{5}{|c|}{ ROOT } & \multicolumn{2}{|c|}{ Standard } \\
\hline & P.S.E & H.E & Ch.E & E.A.E & M.E & Streptomycin & Penicillin \\
\hline Bacillus subtilis & 7 & -- & -- & 8 & 9 & 14 & 10 \\
\hline Staphylococcus aureus & 7 & -- & -- & 8 & 7 & 12 & 10 \\
\hline Proteus vulgaris & -- & -- & -- & -- & -- & 9 & -- \\
\hline Escherichia coli & 8 & -- & -- & 7 & 7 & 10 & 6 \\
\hline Klebsiella pneumoniae & -- & -- & -- & 7 & 7 & 9 & -- \\
\hline
\end{tabular}

(P.S.E. - Petroleum Spirit Extract; H.E. - Hexane Extract; Ch.E. - Chloroform Extract; $\quad$ E.A.E. - Ethyl Acetate Extract; M.E. - Methanol Extract)

'--' Indicates no measurable zone of inhibition. 